\title{
PENGARUH VARIASI ARUS LISTRIK TERHADAP KEKUATAN TARIK GESER LAS TITIK BEDA MATERIAL STAINLESS STEEL DAN ALUMINIUM
}

\author{
Ahmadil Amin ${ }^{1)}$ dan Syarifil Anwar ${ }^{1)}$ \\ ${ }^{1}$ Akademi Teknik Pembangunan Nasional (ATPN) Banjarbaru \\ Email: ahmadilamin718@gmail.com
}

\begin{abstract}
The use of electric current will be related to heat input. Enough heat input is needed to form a good nugget structure so that it can produce maximum connection strength. The nugget structure is influenced by electrode pressure, holding time and the electric current used. By adjusting the parameters of the amount of electric current, the best connection quality will be produced. The purpose of this study is to determine the effect of variations in electric current on the shear tensile strength of dissimilar welding Stainless steel (SS) and Aluminum ( $\mathrm{Al})$. The variation of electric current used is $60 \mathrm{~A}, 70 \mathrm{~A}$ and $80 \mathrm{~A}$. The welding time used is 4 seconds. The test material uses stainless steel material with a thickness of $1.2 \mathrm{~mm}$ and aluminum with a thickness of $0.9 \mathrm{~mm}$. This research was conducted at the Kotabaru Polytechnic Mechanical Laboratory and Malang State Polytechnic Material Test Laboratory. Tests carried out are shear tensile tests according to ASME (American Society of Mechanical Engineering) standards. The results showed that an increase in electric current from $60 \mathrm{~A}$ to $70 \mathrm{~A}$ had an impact on the increase in shear tensile strength. While the increase in electric current from 70 A to 80 A shows a decrease in shear tensile strength. The results of shear tensile testing indicate that the best conditions occur at 70 A electric current which gives a shear tensile strength of $44.109 \mathrm{kN} / \mathrm{mm}^{2}$. The increase in the electric current at the dissimilar welding between Stainless Steel and Aluminum is not directly proportional to the increase in shear stress that occurs. This is because the melting point of each material is different. If the heat generated exceeds the melting point of the material used, the welding results will be damaged.
\end{abstract}

Keywords: Spot Welding, Dissimilar, Stainless Steel, Aluminum.

\section{PENDAHULUAN}

Pesatnya perkembangan dunia perindustrian telah mendorong timbulnya berbagai inovasi dangan gagasan yang baru guna menghasilkan berbagai macam produk yang lebih unggul dan memiliki kualitas yang lebih baik. Dalam industri otomotif, terobosan serta inovasi terbaru sangat diperlukan untuk menjaga dan meningkatkan hasil produksi sehingga pemanfaatan dan penerapan teknologi merupakan hal mutlak yang harus dilakukan, seperti halnya teknologi pengelasan.

Pengelasan merupakan cara penyambungan logam yang paling banyak digunakan karena pengelasan mempunyai kelebihan diantaranya adalah hasil sambungannya lebih kuat Purwaningrum dan Fatchan (2013). Salah satu metode yang digunakan dalam penyambungan lembaran-lembaran plat tipis yang banyak ditemukan dalam industri otomotif seperti pada pengerjaan body atau kerangka mobil adalah las titik (Spot welding). Penyambungan dilakukan dengan cara permukaan plat yang akan disambung ditekan diantara elektroda dan pada saat yang sama arus listrk dialirkan sehingga permukaan logam menjadi panas dan mencair karena adanya resistansi listrik Wiyono (2012).

Penyambungan dengan cara ini relatif lebih praktis dan pengaruh terhadap sifat bahan hasil pengelasan lebih baik dibandingkan dengan cara pengelasan jenis lain, sebab daerah pengaruh panas (HAZ) yang ditimbulkan relatif kecil. Pengelasan ini membutuhkan masukan panas yang cukup dalam waktu yang sigkat untuk mencairkan daerah yang kontak dengan elektroda sehingga menghasilkan proses pencairan setempat. Dengan waktu yang singkat tersebut, maka dibutuhkan arus listrik yang 
besar agar menghasilkan panas yang cukup untuk mencairkan lembaran logam yang kontak terhadap elektroda.

Konsentrasi arus ditentukan oleh luas kontak antara elektroda dan benda kerja, dan jelas bahwa ukuran lasan atau nugget dari logam sangat berkaitan dengan luas kontak ini.

Kuat geser nugget umumnya harus dapat menjamin bahwa bila sambungan diberi tegangan hingga putus, maka putus akan terjadi pada lembaran mengelilingi nugget. Penggunaan arus listrik akan berhubungan dengan masukan panas. Dibutuhkan masukan panas yang cukup untuk membentuk struktur nugget yang baik sehingga dapat menghasilkan kekuatan sambungan yang maksimal. Struktur nugget dipengaruhi oleh tekanan elektroda, waktu tahan dan arus yang digunakan. Dengan mengatur parameter besarnya arus listrik yang diberikan akan dihasilkan kualitas sambungan yang paling baik.

Keunggulan dari pengelasan titik dibandingkan dengan pengelasan lainnya yaitu prosesnya cepat, sehingga cocok untuk produksi massal, suplai panas yang diberikan cukup akurat dan regular, sifat mekanik hasil las kompetitif dengan logam induk dan tidak memerlukan kawat las (Anis, dkk. 2012).

Material yang disambung dapat berbentuk sejenis (similar) maupun berbeda jenis (dissimilar). Pengelasan dissimilar ini dapat lebih rumit dari pada pengelasan similar karena siklus termal yang berbeda dialami masing-masing logam. (Subrammanian dan Jabaraj, 2013).

Stainless Steel dan aluminium adalah material yang banyak digunakan dalam industri otomotif. Aluminium memiliki keuntungan dengan bobotnya yang lebih ringan daripada baja, tetapi peran baja tidak bisa dihilangkan karena berat pada baja dibutuhkan untuk kendaraan dalam rangka menjaga traksi kendaraan. Stainless Steel merupakan material yang memiliki ketahanan terhadap korosi, ketangguhan yang baik dan sifat mampu potong yang baik. Sedangkan aluminium adalah material yang ringan, tahan terhadap korosi dan merupakan konduktor panas dan listrik yang baik. Akan tetapi aluminium juga memiliki beberapa kekurangan seperti sukar untuk dilas dan mudah teroksidasi dengan oksigen. Sebagian besar cacat las yang terjadi pada paduan aluminium adalah retak las dikarenakan pemisahan (Wiryosumarto dan Okumura, 2000). Oleh karenanya kajian untuk mengetahui pengaruh variasi arus listrik terhadap kekuatan tarik sambungan las titik beda material antara stainless steel (SS) dan aluminium (Al) menjadi sangat penting untuk dipelajari.

\section{METODE PENELITIAN}

Penelitian ini diawali dengan studi literature yang berkaitan dengan mesin las titik, Aluminium, Stainless Steel, dan pengujian tarik geser. Kemudian dilanjutkan dengan pembuatan bahan uji standar ASME. Selanjutnya dilakukan pengelasan titik pada bahan uji dari Aluminium dan Stainless Steel dengan variasi arus $60 \mathrm{~A}, 70 \mathrm{~A}$, dan $80 \mathrm{~A}$, waktu pengelasan 4 detik. Selanjutnya dilakukan pengujian tarik geser pada bahan uji hasil las titik dan analisa data hasil pengujian untuk membuat kesimpulan. Diagram Alir penelitian dapat dilihat pada gambar 1 .

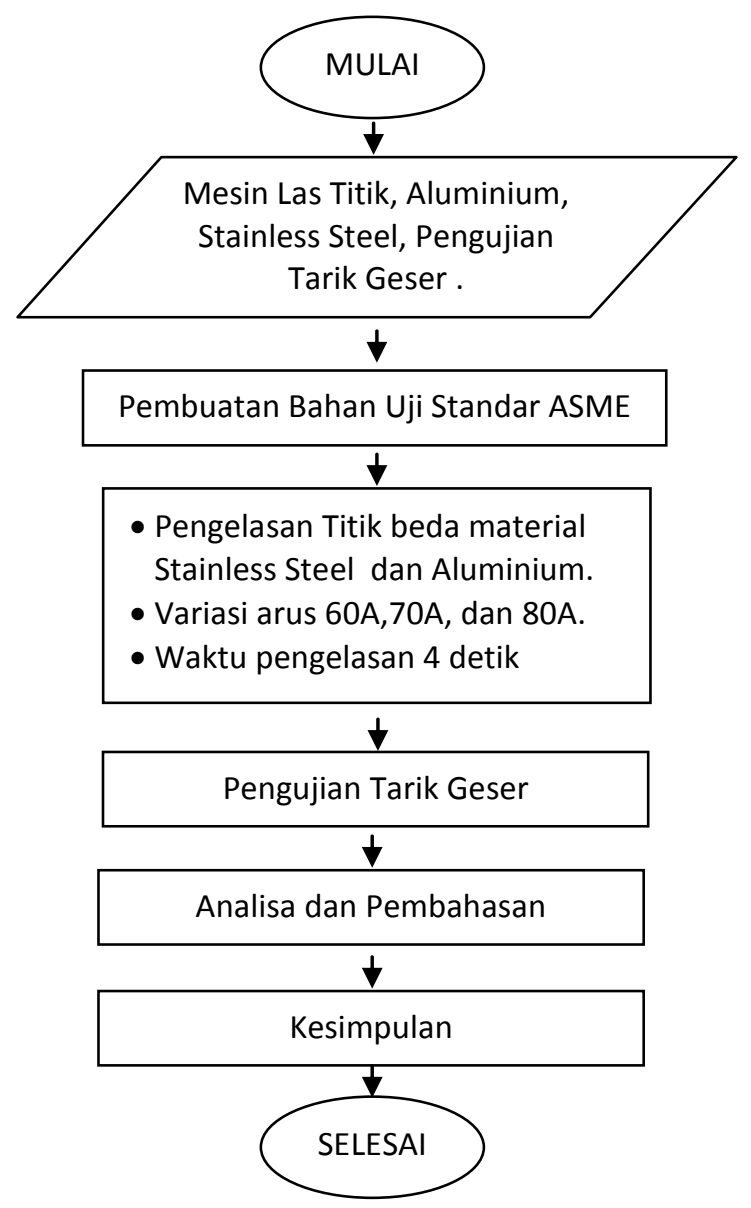

Gambar 1. Diagram alir Penelitian 
Pembuatan bahan uji tarik geser sesuai standar ASME IX (American Society of Mechanical Engineering) menggunakan material Stainless Steel (SS) dan Aluminium (Al). Gambar specimen penyambungan antara plat Aluminium dan plat Stainless Steel seperti pada Gambar 2.

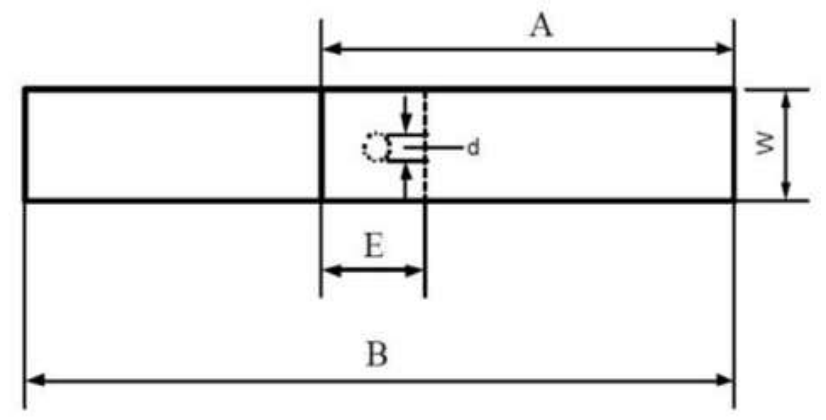

Gambar 2. Spesimen penyambungan Aluminium dan Stainless Steel

Dimana :

(W) Lebar Plat : $30 \quad \mathrm{~mm}$

(A) Panjang Plat: $100 \mathrm{~mm}$

(E) Panjang daerah nugget: $30 \mathrm{~mm}$

(B) Panjang total penyambungan plat: $170 \mathrm{~mm}$

(D) Diameter nugget : $\mathrm{mm}$

Pengelasan dilakukan dengan metode RSW (Resistance Spot Welding). Variasi arus listrik yang digunakan adalah 60 A, 70 A, dan 80 A. Sedangkan waktu pengelasan yang digunakan adalah 4 detik.

Pengujian tarik geser menggunakan bahan uji sesuai standar ASME IX dan dilas menggunakan pengelasan Las Titik. lalu dijepit di mesin uji tarik yang diletakkan secara vertikal, dimana ujungujungnya dijepit dengan penjepit yang ada pada mesin uji tarik. Uji tarik geser dilakukan di Laboratorium Uji Bahan Polteknik Negeri Malang.

\section{HASIL DAN PEMBAHASAN}

\section{Pengaruh Arus Listrik Terhadap Kekuatan Tarik Geser}

Pengujian tarik geser dilakukan pada bahan uji untuk mengetahui bagaimana pengaruh arus listrik terhadap kekuatan tarik geser las titik beda material antara Stainless Steel dan Aluminium.

Proses penyambungan antara stainless steel dan aluminium menggunakan pengelasan titik sulit dilakukan karena titik leburnya yang jauh berbeda. Logam stainless steel cenderung lebih kuat dibandingkan aluminium, hal ini dapat dilihat dari letak sobekan berada di daerah HAZ aluminium dan logam lasnya menempel pada stainless steel. Tetapi melalui pengaturan arus listrik yang tepat, akhirnya proses penyambungan dapat dilakukan. Pada Tabel 1 dapat dilihat hasil pengujian tarik geser dari masingmasing bahan uji. Terlihat bahwa kenaikan arus listrik berbanding lurus dengan kenaikan diameter nugget las, tetapi hal yang sama tidak terjadi pada kekuatan tarik geser yang terjadi.

Tabel 1. Hasil pengujian tarik geser

\begin{tabular}{ccc}
\hline $\begin{array}{c}\text { Kuat Arus Listrik } \\
\text { (Amper) }\end{array}$ & $\begin{array}{c}\text { Diameter } \\
\text { Nugget }(\mathrm{mm})\end{array}$ & $\begin{array}{c}\text { Kekuatan Tarik } \\
\text { Geser }\left(\mathrm{kN} / \mathrm{mm}^{2}\right)\end{array}$ \\
\hline 60 & 7,5 & 22,039 \\
70 & 8 & 44,109 \\
80 & 8,5 & 31,847
\end{tabular}

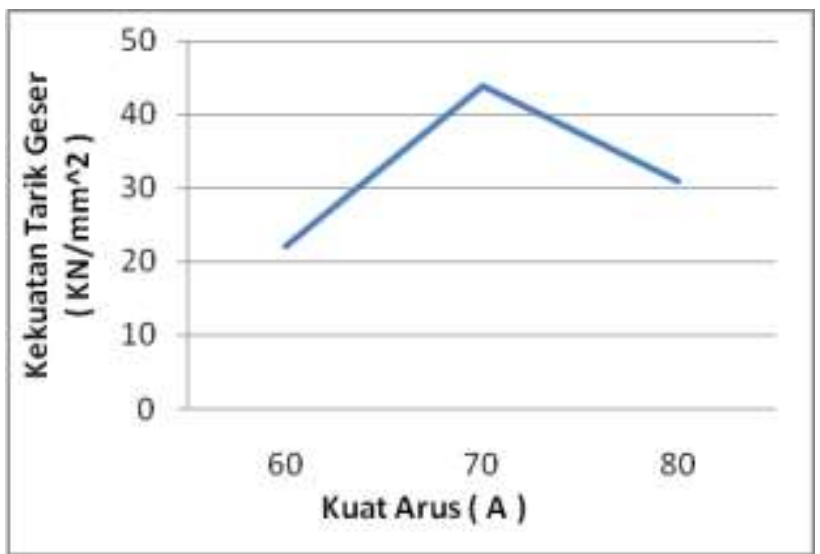

Gambar 3. Grafik pengaruh arus listrik terhadap kekuatan tarik geser.

Gambar 3 menunjukkan bahwa peningkatan arus listrik dari 60 A ke 70 A berdampak pada kenaikan kekuatan tarik geser. Sedangkan peningkatan arus listrik dari 70 A ke 80 A memperlihatkan penurunan kekuatan tarik geser. Pada Arus listrik 60 A didapatkan nilai kekuatan tarik geser sebesar 22,039 kN/mm². Pada arus listrik 70 A didapatkan kekuatan tarik geser sebesar 44,109 $\mathrm{kN} / \mathrm{mm}^{2}$. Sedangkan pada arus listrik $80 \mathrm{~A}$ diperoleh nilai kekuatan tarik geser sebesar $31,847 \mathrm{kN} / \mathrm{mm}^{2}$. Hasil pengujian tarik menunjukkan bahwa kondisi terbaik terjadi pada arus listrik 70 A yang memberikan kekuatan tarik geser sebesar 44,109 $\mathrm{kN} / \mathrm{mm}^{2}$.

Dengan meningkatnya arus pengelasan didapatkan kekuatan tarik geser yang semakin 
rendah. hal ini dikarenakan arus pengelasan yang semakin besar akan menghasilkan daerah logam las yang lebar serta penembusan yang dalam sehingga menghasilkan kekuatan tarik yang rendah dan menambah kerapuhan (Arifin, 1997). Hal ini sesuai dengan diameter logam las (nugget) yang terbentuk, dimana seiring dengan meningkatnya arus pengelasan maka diameter nugget semakin besar.

Semakin besar arus yang digunakan, maka masukan panas yang terjadi juga semakin besar. Tetapi tidak selamanya sambungan menjadi lebih baik, pada sambungan las titik beda material terdapat suatu kondisi dimana semakin besar arus tetapi hasil lasnya rusak, hal ini terjadi karena titik lebur pada setiap material berbeda - beda, jika panas yang dihasilkan melebihi titik lebur material yang digunakan, maka hasil pengelasan akan rusak. Konduktivitas thermal material yang berbeda-beda juga dapat menjadi penyebab terjadinya perbedaan laju pendinginan yang terjadi pada proses rekristalisasi.

Dengan melakukan pengaturan arus listrik sebesar 70A dengan waktu pengelasan selama 4 detik dapat memberikan kekuatan tarik yang paling optimal dibandingkan parameter pengelasan lainnya.

\section{KESIMPULAN}

Data pengujian tarik geser pada hasil las titik beda material stainless steel dan aluminium menunjukkan bahwa kenaikan arus listrik tidak berbanding lurus dengan kenaikan tegangan tarik geser yang terjadi. Kondisi optimal terjadi pada pengelasan titik dengan arus listrik $70 \mathrm{~A}$ dan waktu pengelasan 4 detik, yang memberikan kekuatan tarik geser sebesar 190,920 kN/mm². Hal ini disebabkan karena titik lebur dan konduktivitas thermal yang berbeda - beda pada setiap material.

\section{DAFTAR PUSTAKA}

Purwaningrum, Y. dan Fatchan, M. 2013. Pengaruh arus listrik terhadap karakteristik fisik mekanik sambungan las titik logam dissimilar Al-Steel. Jurnal Teknik Mesin, 15 (1)

Wiyono, T. 2012. Penentuan pengelasan dissimilar alumunium dan plat baja karbon rendah dengan variasi waktu pengelasan dan arus listrik. Journal Foundry, 2(1).
Anis, M., Irsyadi, A. dan Ferdian, D. 2009. Studi lapisan intermetalik $\mathrm{Cu} \mathrm{Sn}$ pada ujung elektroda dalam pengelasan titik baja galvanis. Jurnal Teknologi, 13 (2).

Subrammanian, A. dan Jabaraj, B.D. 2013. Research on resistance spot welding of stainless steel. International Journal of Scientifik \& Engineering research, 4 (12).

Wiryosumarto, H. dan Okumura, T. 2000. Teknologi Pengelasan Logam. Jakarta. PT. Pradnya Paramita.

Arifin, S. 1997. Las listrik dan Otogen. Jakarta: Ghalia Indonesia. 